Ferrata Storti Foundation

\title{
Human stem cells transplanted into the rat stroke brain migrate to the spleen via lymphatic and inflammation pathways
}

Haematologica 2019

Volume 104(5):1062-1073

\section{Correspondence: \\ CESARIO V. BORLONGAN \\ cborlong@health.usf.edu \\ Received: September 11, 2018. \\ Accepted: November 30, 2018. \\ Pre-published: December 4, 2018.}

doi:10.3324/haematol.2018.206581

Check the online version for the most updated information on this article, online supplements, and information on authorship \& disclosures: www. haematologica.org/content/104/5/1062

\section{(C)2019 Ferrata Storti Foundation}

Material published in Haematologica is covered by copyright. All rights are reserved to the Ferrata Storti Foundation. Use of published material is allowed under the following terms and conditions:

https://creativecommons.org/licenses/by-nc/4.0/legalcode. Copies of published material are allowed for personal or internal use. Sharing published material for non-commercial purposes is subject to the following conditions:

https://creativecommons.org/licenses/by-nc/4.0/legalcode, sect. 3. Reproducing and sharing published material for commercial purposes is not allowed without permission in writing from the publisher.

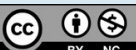

\author{
Kaya Xu, ${ }^{1,2}$ Jea-Young Lee, ${ }^{1}$ Yuji Kaneko, ${ }^{1}$ Julian P. Tuazon, ${ }^{1}$ Fernando Vale, ${ }^{1}$ \\ Harry van Loveren ${ }^{1}$ and Cesario V. Borlongan ${ }^{1}$
}

${ }^{1}$ Center of Excellence for Aging and Brain Repair, Department of Neurosurgery and Brain Repair, University of South Florida College of Medicine, Tampa, FL, USA and 'Department of Neurosurgery, The Affiliated Hospital of Guizhou Medical University, China

\section{ABSTRACT}

$\longrightarrow$ espite mounting evidence of a massive peripheral inflammatory response accompanying stroke, the ability of intracerebrally transplanted cells to migrate to the periphery and sequester systemic inflammation remains unexamined. Here, we tested the hypothesis that human bone marrow mesenchymal stromal cells intracerebrally transplanted in the brain of adult rats subjected to experimental stroke can migrate to the spleen, a vital organ that confers peripheral inflammation after stroke. Sham or experimental stroke was induced in adult SpragueDawley rats by a 1 hour middle cerebral artery occlusion model. One hour after surgery, rats were intracerebrally injected with human bone marrow mesenchymal stromal cells $\left(3 \times 10^{5} / 9 \mu \mathrm{L}\right)$, then euthanized on day 1,3 , or 7 for immunohistochemical assays. Cell migration assays were performed for human bone marrow mesenchymal stromal cells using Boyden chambers with the bottom plate consisting of microglia, lymphatic endothelial cells, or both, and treated with different doses of tumor necrosis factor- $\alpha$. Plates were processed in a fluorescence reader at different time points. Immunofluorescence microscopy on different days after the stroke revealed that stem cells engrafted in the stroke brain but, interestingly, homed to the spleen via lymphatic vessels, and were propelled by inflammatory signals. Experiments using human bone marrow mesenchymal stromal cells co-cultured with lymphatic endothelial cells or microglia, and treated with tumor necrosis factor- $\alpha$, further indicated the key roles of the lymphatic system and inflammation in directing stem cell migration. This study is the first to demonstrate brain-to-periphery migration of stem cells, advancing the novel concept of harnessing the lymphatic system in mobilizing stem cells to sequester peripheral inflammation as a brain repair strategy.

\section{Introduction}

Ischemic stroke continues to stand as a leading cause of death and disability worldwide, with an ongoing need for effective therapies. ${ }^{1}$ Cell-based therapies have emerged as a promising modality for stroke treatment, yet a complete understanding of their mechanisms remains elusive..$^{2 \cdot 4}$ The study of stem cell therapy for stroke has focused primarily on the effects of the grafted cells within the local brain tissue, despite the recognition of a peripheral inflammatory response exacerbating the pathological outcomes in the stroke brain. ${ }^{5,6}$ Following stroke, a compromised blood-brain barrier (BBB) allows peripheral major histocompatibility complex class II (MHC-II)-positive immune cells - including neutrophils, T cells, and monocytes/macrophages ${ }^{7}$ - to infiltrate the brain parenchyma, perpetuating a state of cerebral inflammation. ${ }^{8.10}$ Pharmacological and cell-based anti-inflammatory methods which attenuate cerebral and systemic inflammation have been shown to improve stroke outcomes. ${ }^{11,12}$ Thus, an understanding of how stem cells sequester and modulate peripheral inflammation is key for furthering the application of stem 
cell therapies in stroke and other neurological disorders with pathologies characterized by aberrant inflammation.

The spleen is a major contributor to the peripheral inflammatory response observed following stroke. ${ }^{13,14}$ Acting as a reservoir for leukocytes, the spleen is the primary disseminator of inflammatory cells in response to injury. ${ }^{15}$ This splenic response, paired with the compromised $\mathrm{BBB}$ following stroke, contributes to the infiltration of pro-inflammatory mediators into the brain and worsened outcomes. ${ }^{16-18}$ We have previously reported that human bone marrow mesenchymal stromal cells (hBMSC) delivered intravenously preferentially migrate to the spleen, dampening systemic inflammation. ${ }^{19}$ These findings support the therapeutic potential of targeting the peripheral inflammatory response via the spleen to abrogate neuroinflammation, in addition to implicating stem cells as inflammation-homing biologics.

In light of the spleen and peripheral inflammation being principal culprits in neuroinflammatory-induced cell death processes ${ }^{20,21}$ the recently characterized cerebral lymphatic system opens a new avenue of research in stem cell therapies for neurological disorders. ${ }^{22}$ Cognizant that the spleen is a major destination for lymphatic drainage, the cerebral lymphatic system could serve as an efficient route for brain-to-spleen stem cell migration. To date, this notion of intracerebrally transplanted stem cells migrating remotely away from the implantation sites in ischemic regions, albeit outside the brain, has not been investigated. Here, we report for the first time that stem cells can migrate from the cerebrum to the periphery via lymphatic vessels, likely amplified by stroke-induced local and peripheral inflammation. This line of investigation advances the concept of targeting the source of the peripheral inflammatory response by harnessing lymphatic vessel-directed migration of stem cells. The present study also provides valuable data toward a novel understanding of how intracerebral transplantation of stem cells functions to repair the damaged brain through peripheral effectors.

\section{Methods}

\section{Animals and housing}

All experiments were approved by the Institutional Animal Care and Use Committee of the University of South Florida, Morsani College of Medicine and were conducted in compliance with the National Institutes of Health Guide for the Care and Use of Laboratory Animals and the United States Public Health Service's Policy on Humane Care and Use of Laboratory Animals. All experiments were carried out on 2-month old SpragueDawley male rats (Harlan Laboratories, Indianapolis, IN, USA) and rats were either exposed to sham $(\mathrm{n}=6)$ or stroke surgery, with the latter further classified as mild $(n=9)$ or severe $(n=9)$ based on the severity of the stroke as evidenced by pathological outcomes. There were six animals in the sham-treated group, nine in the mild stroke group, and nine in the severe stroke group across all treatments, and all animals were treated with hBMSC.

\section{Stroke surgery}

Animals underwent middle cerebral artery occlusion surgery as described in our previous study. ${ }^{23}$ Sham surgery involved exposing and isolating the common carotid and internal carotid arteries before closing the incision. Severe stroke was induced by $60 \mathrm{~min}$ intraluminal filament occlusion of the right internal carotid artery with simultaneous ligation of the contralateral (left) common carotid artery for $30 \mathrm{~min}$. In contrast, mild stroke was induced by 60 min occlusion of the right internal carotid artery, without ligating the left common carotid artery.

\section{Cell preparation}

hBMSC and bEnd.3-expressing lymphatic vessel endothelial hyaluronan receptor-1 (LYVE-1) were purchased from the American Type Culture Collection (ATCC, VA, USA). The immortalized BV-2 murine microglial cells $\mathrm{s}^{24}$ were maintained in Dulbecco modified Eagle medium (Gibco, MA, USA). Immortalized bEnd.3 and BV-2 cells were used to better manage the growth of these cells in culture over longer periods of time. ${ }^{25}$ For transplantation preparation, hBMSC density was adjusted to $7.5 \times 10^{6}$ cells in 216 $\mu \mathrm{L}$ of phosphate-buffered saline. For cell migration, the cell density was adjusted to $1 \times 10^{6}$ cells in $5 \mathrm{~mL}$ fluorescent medium (ThermoFisher, MA, USA). Thereafter, cells were incubated with 1,1'-dioctadecyl-3,3,3',3'-tetramethylindodicarbocyanine perchlorate ( $\mathrm{DiD}$, Invitrogen, OR, USA) for $30 \mathrm{~min}$, to aid the visualization of hBMSC migration.

\section{Transplantation}

One hour after middle cerebral artery occlusion surgery, rats were anesthetized and hBMSC were injected intracerebrally into the striatum and cortex of the ischemic hemisphere over $10 \mathrm{~min}$ as previously described. ${ }^{26}$ Within a single needle pass, two deposits of hBMSC were made in the striatum (DV=5.0 $\mathrm{mm}$ and $\mathrm{DV}=4.0 \mathrm{~mm}$ ) and one deposit of $\mathrm{hBMSC}$ was made in the cortex $(\mathrm{DV}=3.0 \mathrm{~mm}$ ) for a total of three separate deposits $(\mathrm{AP}=+0.5 \mathrm{~mm}$, $\mathrm{ML}=+2.8 \mathrm{~mm}, \mathrm{DV}=5.0 \mathrm{~mm}, 4.0 \mathrm{~mm}$, and $3.0 \mathrm{~mm}){ }^{26}$ Each deposit contained $1 \times 10^{5}$ cells $/ 3 \mu \mathrm{L}$ phosphate-buffered saline for a total of $3 \times 10^{5}$ cells suspended in $9 \mu \mathrm{L}$ phosphate-buffered saline for the entire transplant regimen per animal.

\section{Brain and organ harvesting, fixation, and sectioning}

Rats were euthanized under deep anesthesia on day 1, day 3, or day 7 after transplantation for ex vivo imaging analysis, as described in our past study. ${ }^{21}$

\section{Measurement of infarct area}

Hematoxylin and eosin staining was performed to confirm the core infarct injury of our stroke model as shown in our previous studies. ${ }^{24,27}$

\section{Immunohistochemistry assays}

Human nuclei ( $\mathrm{HuNu}$ ) and OX6 staining was performed as described in our previous study. ${ }^{21}$ Details of the immunohistochemistry assays are described in the Online Supplementary Material.

\section{Cell migration assay}

The cell migration assay was performed using a Falcon ${ }^{\mathrm{TM}}$ FlouroBlok ${ }^{\text {TM }}$ 96-well HTS insert system with $3.0 \mu \mathrm{m}$ pores (Life Science, NC, USA). BV2 and bEnd. 3 cells were fed with fresh growth medium at the bottom of the lower chamber in a 96-well plate. There were three groups in the bottom cell: BV2, bEnd.3, and BV2+bEnd.3. The cell density was adjusted to $2 \times 10^{4}$ cells in $200 \mu \mathrm{L}$ growth medium/well overnight. Cells were treated with different doses of tumor necrosis factor-alpha (TNF- $\alpha$; $0 \mathrm{ng} / \mathrm{mL}, 25$ $\mathrm{ng} / \mathrm{mL}, 50 \mathrm{ng} / \mathrm{mL}$, or $100 \mathrm{ng} / \mathrm{mL}$ ) in an incubator overnight. The details of the cell migration assay are described in the Online Supplementary Material.

\section{Statistical analysis}

All data are expressed as the mean \pm standard error of mean and statistically evaluated using one-way or two-way analysis of vari- 
ance (ANOVA) followed by a Bonferroni test (GraphPad version 5.01). Comparisons with a $P$ value $<0.05$ were considered statistically significant.

\section{Results}

\section{Infarct sizes}

Hematoxylin and eosin staining indicated the presence of infarcts in the animals with mild and severe stroke. Percentages of infarct lesion area were rated accordingly: mild $\leq 10 \%$, and severe $>10 \%$ (Figure $1 \mathrm{~B}$ ). The groups with severe stroke had significantly higher percentages of infarct area than those with mild stroke at all time points $(P<0.001 ; P<0.01)$. Furthermore, transplanting hBMSC grafts did not reduce infarct sizes and no significant outliers were detected across the treatment groups (Figure 1A).

\section{Survival of human bone marrow mesenchymal stromal cells in the brain and spleen}

Confocal microscopy with $\mathrm{HuNu}$ staining was used to analyze hBMSC survival and detected positive $\mathrm{HuNu}$ expression in brains transplanted with hBMSC (Figure 2A). Additionally, HuNu-positive cells in the spleen indicated that intracerebrally injected stem cells migrated from the brain to the spleen (Figure 2B). On day 1, the number of HuNu-positive cells in the brains of the group with severe stroke was significantly higher than that of the group with mild stroke and the sham-treated group $(P<0.001)$. On day 3 , the numbers of HuNu-positive cells in the brains of the groups with mild and severe stroke were significantly higher than the number in the shamtreated group $P<0.01$ ) (Figure $2 \mathrm{C}$ ). On all days, the groups with mild and severe stroke had significantly higher numbers of hBMSC in the spleen compared to the numbers in the spleen of the sham-treated group $(P<0.001)$ (Figure $2 \mathrm{D})$. When comparing between days and within experimental groups, there were no significant differences in either the brain or the spleen, between the sham-treated groups $(P>0.05)$ but there were significant differences between the groups with mild stroke and between the groups with severe stroke $(P<0.001)$ (Figure $2 \mathrm{C}, \mathrm{D})$. The detection of surviving $\mathrm{hBMSC}$ in the brain and spleen was most robust on day 3 , with the highest number of cells identified in the groups with severe stroke (Figure 2C,D).

\section{Human bone marrow mesenchymal stromal cells were visualized within lymphatic vessels in the brain and spleen}

To further elucidate whether transplanted stem cells could migrate from the brain to the peripheral immune organs through the lymphatic system, we co-stained for HuNu to visualize hBMSC, and LYVE-1 to visualize lymphatic endothelial cells. In all animals, few HuNu-positive cells were found within brain lymphatic vessels, which expressed LYVE-1, at any time point (Figure 3A). Additionally, there were no significant differences in the quantity of HuNu and LYVE-1 co-localization in the brain at any time point between sham-treated animals and those with mild or severe stroke $(P>0.05)$ (Figure $3 \mathrm{C})$. In contrast, many hBMSC were visualized within all transplanted rats' splenic lymphatic vessels on all days (Figure 3B). Animals with mild and severe strokes displayed significantly more hBMSC within splenic lymphatic vessels than did sham-treated animals on any day on which measurements were made $(P<0.05)$ (Figure $3 \mathrm{D})$. On day 3 , the group with severe stroke expressed the greatest amount of co-localized cells in the spleen $(P<0.001)$.

\section{Stroke induces neuroinflammation in the brain and spleen}

To reveal any upregulation of stroke-induced neuroinflammation, we stained brain and spleen sections with OX6 to label microglia possessing the proinflammatory M1 phenotype (Figure 4A,B). OX6 expression in the brain and spleen was significantly higher in the groups with mild and severe stroke than in the sham-treated group at all time points $(P<0.01 ; P<0.001)$ (Figure 4C,D). On day 3, the brains and spleens of animals groups with mild and severe stroke, but not those of the sham-treated group, exhibited significantly more OX6-positive cells than they
A

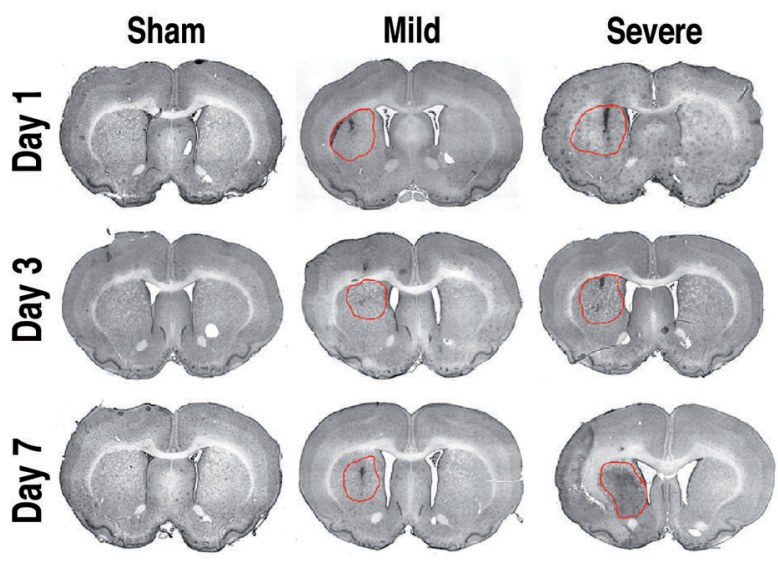

B

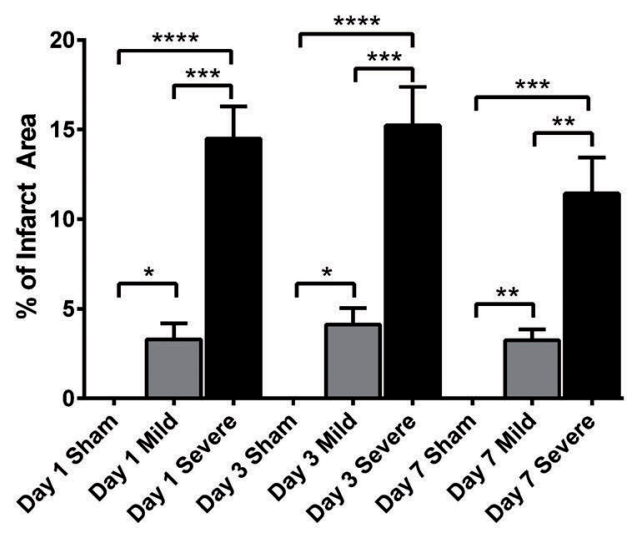

Figure 1. Infarct sizes in a rat model of stroke. (A) Representative hematoxylin and eosin-stained brain sections from rats that had undergone sham surgery (sham), surgery to induce a mild stroke (mild) or surgery to induce a severe stroke (severe). One hour after sham, mild or severe stroke surgery, rats were intracerebrally injected with human bone marrow mesenchymal stromal cells. Brains from animals with mild or severe stroke show ischemic lesions. Red circles indicate infarct areas. (B) Bar graph depicting infarct size in stroke animals. The infarct area in the ipsilateral hemisphere is expressed as a percentage of the area of the contralateral hemisphere. Values are indicated as means \pm standard error of mean. Significance bars: ${ }^{*} P<0.05 ; * * P<0.01 ; * * * P<0.001 ; * * * * P<0.0001$. 
did on other days, with the highest concentration found in the group with severe stroke $(P<0.001)$ (Figure 4C,D).

\section{X6-positive cells localized near or within lymphatic vessels in the brain and spleen}

OX6-positive cells localized near or within lymphatic vessels in the brain (Figure 5A) and spleen (Figure 5B) and their quantity was higher in animals with mild or severe stroke than in sham-treated animals. Groups with mild or severe stroke had more OX6-positive cells close to or within lymphatic vessels on day 3 than at other time points. OX6 expression near or within lymphatic vessels in the brain and spleen was significantly higher in the groups with mild and severe stroke than in the shamtreated group at all time points $(P<0.05 ; P<0.01 ; P<0.001)$ (Figure $5 \mathrm{C}, \mathrm{D})$. On day 3 , the brains and spleens of the groups with mild and severe stroke, but not sham-treated group brains and spleens, exhibited significantly more OX6-positive cells next to or within lymphatic vessels than they did on other days, with the highest concentration found in the group with severe stroke $(P<0.01)$ (Figure 5C,D).
Human specific phagocytic marker CD68, anti-apoptosis inhibitor 5 and neuronal marker triple staining in the brain and spleen

Stroke-induced ischemic and apoptotic neurons result in inflammation. To test whether transplanted hBMSC can phagocytose ischemic neuronal cells in the brain and migrate to the periphery, we stained brain and spleen sections with human specific phagocytic marker CD68, antiapoptosis inhibitor 5, and anti-160kD neurofilament medium antibody-rat specific neuronal marker. The human specific phagocytic marker CD68 was employed to label the transplanted hBMSC demonstrating phagocytic activity, the anti-apoptosis inhibitor 5 was utilized to mark rat neurons undergoing apoptosis, and the anti$160 \mathrm{kD}$ neurofilament medium antibody-rat specific neuronal marker was used to label rat neurons. CD68 expression was negligible for these hBMSC in vitro, suggesting that phagocytic expression may be triggered by the ischemic microenvironment of the transplant site. In the brain and in the spleen, apoptotic neuronal cells were found inside phagocytic human cells (Figure 6A,B). The amounts of cells positive for all three staining labels were
A

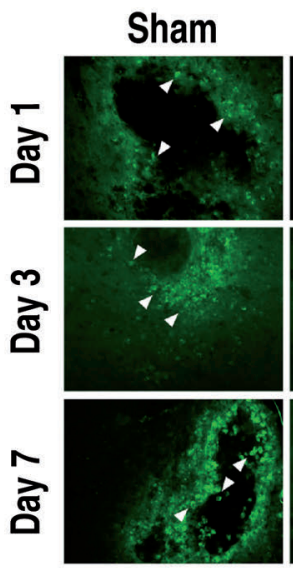

B

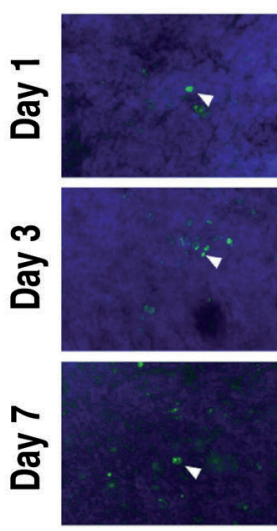

Mild
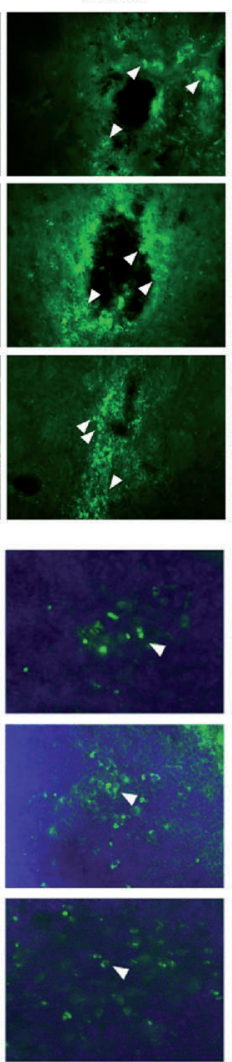

Severe
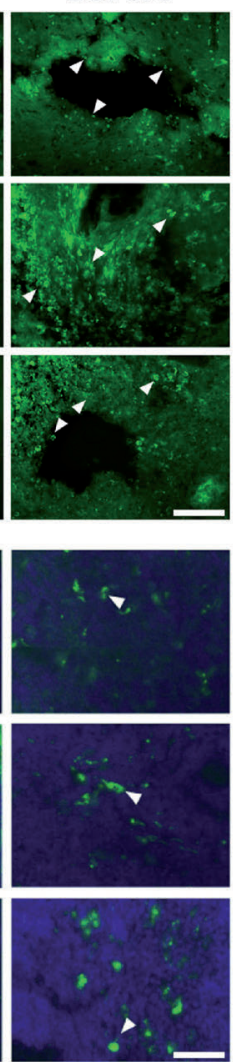

C

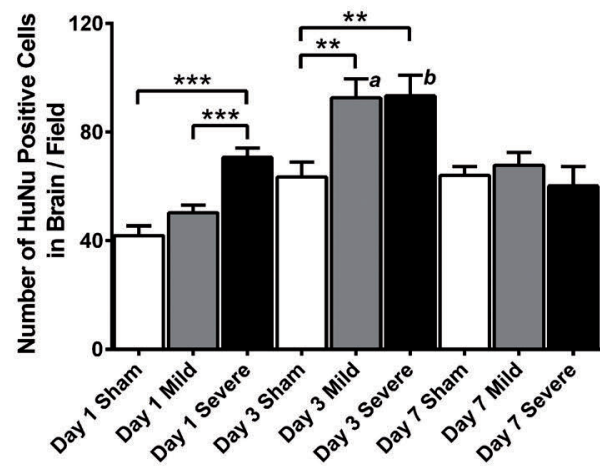

D

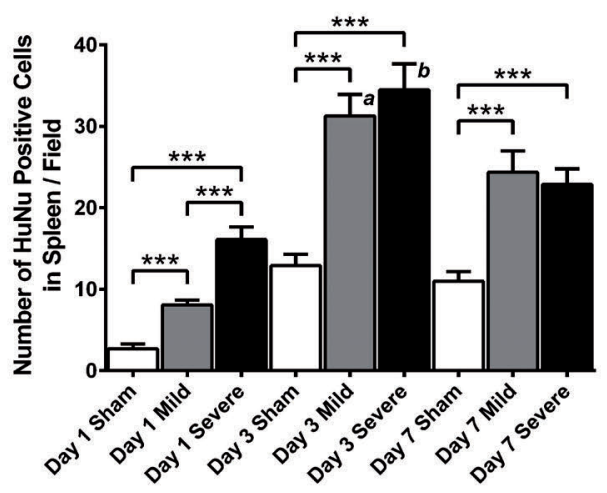

Figure 2. Survival of human bone marrow mesenchymal stromal cells in the brain and spleen. (A) In the brain, transplanted human bone marrow mesenchymal stromal cells (hBMSC) express antigens for human nuclei (HuNu). The hBMSC grafts in the brain were positively stained with HuNu. (B) Representative merged images showing co-localization of HuNu-positive cells and 4,6-diaminodino-2-phenylindole (DAPI) for hBMSC in the spleen. (A and B) Arrow heads indicate HuNu-positive cells. Scale bars $=100 \mu \mathrm{m}$. Green: HuNu; blue: DAPI. (C and D) Quantitative analyses of the estimated number of HuNu-positive hBMSC in the brain (C) and in the spleen (D) of stroke and sham-treated animals revealed more HuNu-positive cells survived in the brain and migrated to the spleen on day 3 , especially in the groups with severe stroke. Significance bars: $* * P<0.01 ; * * * P<0.001$. (C) a: The group with mild stroke had significantly more HuNu-positive cells in the brain on day 3 than on other days $(P<0.01)$; $b$ : the group with severe stroke had significantly more HuNu-positive cells in the brain on day 3 than on other days $(P<0.01)$. (D) a: The group with mild stroke had significantly more HuNu-positive cells in the spleen on day 3 than on other days $(P<0.001)$; b: the group with severe stroke had significantly more HuNu-positive cells in the spleen on day 3 than on other days $(P<0.001)$. 
significantly higher in brains and spleens of the groups with mild and severe stroke than in sham-treated group brains and spleens $(P<0.001)$ (Figure 6C,D). Animals with mild or severe stroke, but not sham-treated animals, had significantly more triple stain-positive cells in both organs on day 3 , relative to other days, especially the group with severe stroke $(P<0.05)$ (Figure 6C,D).

\section{Human bone marrow mesenchymal stromal cells} migrate toward bEnd.3, BV2, and bEnd.3+BV2 cells, a process enhanced by tumor necrosis factor- $\alpha$

\section{treatment}

hBMSC migrated toward lymphatic endothelial cells (bEnd.3, expressing LYVE-1), microglia (BV2), and a combination of bEnd.3+BV2 cells in in vitro cell migration assays (Figure 7A-F). Administering TNF- $\alpha$ escalated hBMSC migration in a dose-dependent manner. At different time points $(0 \mathrm{~h}-72 \mathrm{~h})$, the density of hBMSC migrating toward bEnd.3 (Figure 7A,B), BV2 (Figure 7C,D), and bEnd.3+BV2 (Figure 7E,F) increased significantly with pro- gressively higher concentrations of TNF- $\alpha \quad(P<0.05)$. Additionally, the density of hBMSC migration to bEnd.3, BV2, and bEnd.3+BV2 cells increased over time (Figure $7 \mathrm{~B}, \mathrm{D}, \mathrm{F})$. Cell migration to bEnd.3+BV2 peaked at $48 \mathrm{~h}$ with the highest TNF- $\alpha$ dose (Figure 7F), which is consistent with the in vivo results showing that the number of hBMSC was highest in the group with severe stroke on day 3 (Figure 2D). BV2 cells had the highest density of hBMSC migration relative to bEnd. 3 and bEnd.3+BV2 groups at all time points, demonstrating that hBMSC preferentially migrated to BV2 cells $(P<0.01)$ (Figure 7G-J).

\section{Discussion}

The brain is traditionally known to play an essential role in governing and coordinating systemic homeostasis. In recent years, it has become increasingly clear that brain health and neurological diseases are intimately associated with other physiological systems. ${ }^{28,29}$ Growing evidence
A

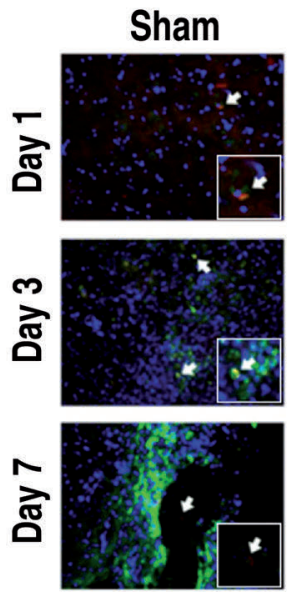

B
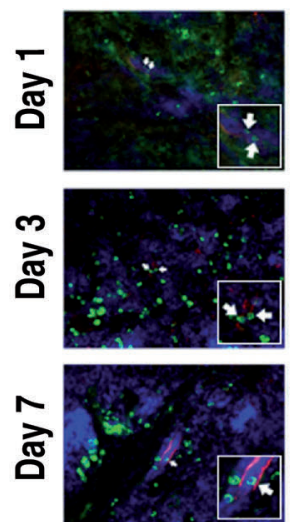
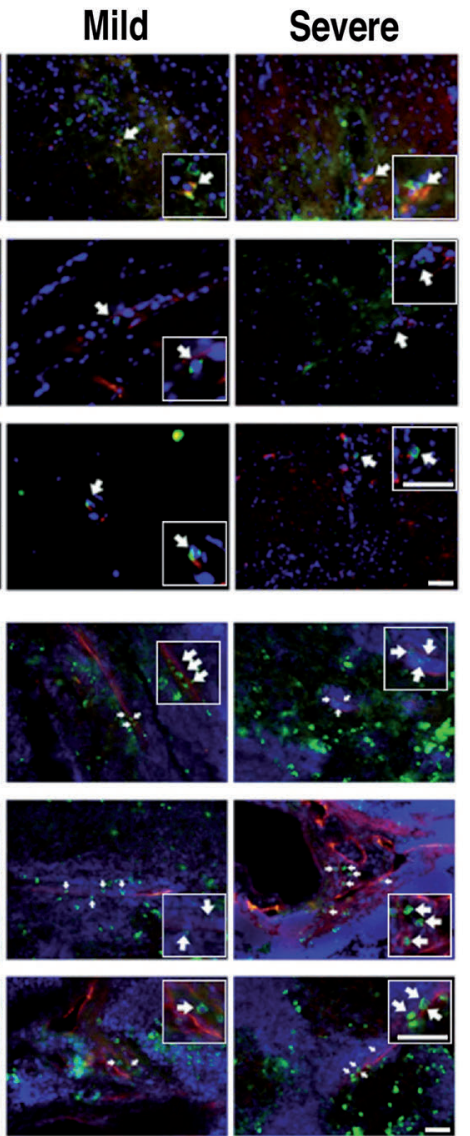

C

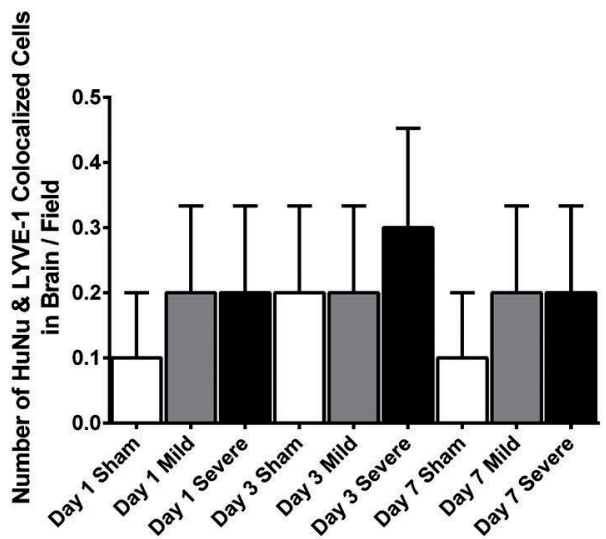

D

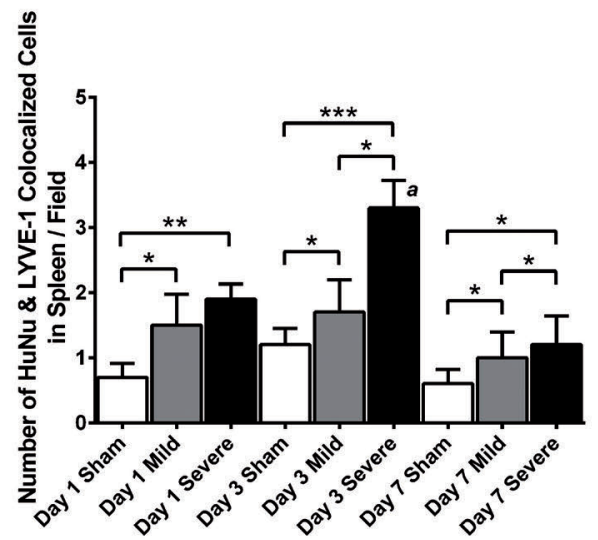

Figure 3. Visualization of human bone marrow mesenchymal stromal cells within lymphatic vessels in the brain and spleen. (A and B) Human bone marrow mesenchymal stromal cells (hBMSC) were stained with human nuclei (HuNu) and lymphatic endothelial cells were stained with lymphatic vessel endothelial hyaluronan receptor-1 (LYVE-1) to reveal co-localization of hBMSC and lymphatic endothelial cells in the brain (A) and spleen (B). Arrow heads indicate co-localization of HuNupositive and LYVE-1-positive cells and show that hBMSC localized within lymphatic vessels in the brain and spleen. Small boxes show 40x magnification. Scale bars $=100 \mu \mathrm{m}$. Red: LYVE-1; green: HuNu; blue: DAPI. (A) Images were taken close to the dural sinuses in the brain. (B) Images were taken near to the gate of the spleen, close to the white pulp in the spleen. (C and D) Quantitative analyses of the estimated number of co-localized HuNu-positive and LYVE-1-positive cells in the brain (C) and in the spleen (D) of animals with mild or severe stroke and sham-treated animals. Significance bars: $* P<0.05$; $* * P<0.01$; $* * * P<0.001$. (C) No significant differences were found in the magnitude of co-localization in the brain between sham-treated groups and those with mild or severe stroke on all days that the assessments were made $(P>0.05)$. (D) Groups with mild and severe stroke displayed significantly higher quantities of co-localization in the spleen relative to the sham-treated group on all days the measurements were made $(* P<0.05)$. Staining overlap was most prominent on day 3 , especially in the groups with severe stroke. a: The group with severe stroke had significantly more co-localized cells in the spleen on day 3 than on other days $(P<0.001)$. 
suggests that an immense peripheral inflammatory response follows stroke, yet investigations into stem cell therapy have not probed whether stem cells transplanted intracerebrally are capable of migrating to the periphery and alleviating systemic inflammation. Previously, we administered hBMSC intravenously in experimental rat models of stroke and the transplanted cells preferentially migrated to the spleen, demonstrated greater survival in the spleen than in the brain, and ameliorated strokeinduced neurostructural deficits and chronic inflammation. ${ }^{19}$ Here, we showed that lymphatic pathways and inflammatory signals enable stem cells to migrate to the spleen after intracerebral transplantation in a stroke brain (Figure 8).

Preferential migration toward the site of pathological signals is critical for stem cell transplantation to achieve its therapeutic potential. Such deposition of systemically delivered stem cells into the spleen after stroke is accompanied by reduced necrotic and apoptotic cell death in the brain, decreased motor and cognitive deficits, and a dampened splenic inflammatory response..$^{12,30-33}$ This sequestration of neurodegeneration by suppressing systemic inflammation originating from the spleen was previously demonstrated in stroke animals that had their spleen removed or were transplanted with human umbilical cord cells in the acute stage of stroke. . $^{12,30}$

The present in vivo imaging revealed the migration of intracerebrally transplanted hBMSC to the spleen in the acute stage. The highest numbers of these cells were found on day 3 in both brain and spleen. Transient blockage of the contralateral common carotid artery caused more intense ischemia in the brain tissue of groups with severe stroke, producing much higher levels of inflammatory factors. This increased inflammatory response heightens the migratory action of the transplanted stem cells. In animal models of focal cerebral ischemic stroke, recruitment of multiple inflammatory cell types such as neutrophils within the ischemic brain occurs within 30 minutes to a few hours after the stroke, peaking within the first 3 days. ${ }^{34,35}$ hBMSC have immunomodulatory capacities, are multipotent, and tend to migrate to sites of tissue injury/inflammation, making them promising effectors for tissue regeneration. ${ }^{36-40}$

Lymphatic vessels, in addition to draining interstitial fluids, allow cells to travel from tissues to draining lymph nodes. ${ }^{41}$ Therefore, we examined whether the cerebral
A

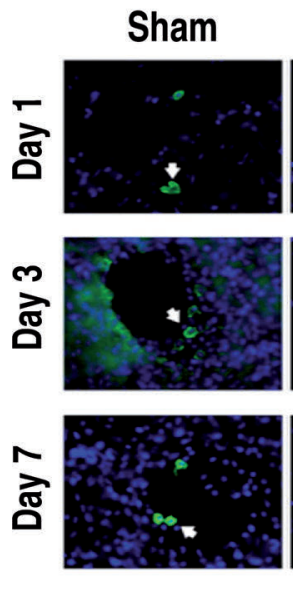

B

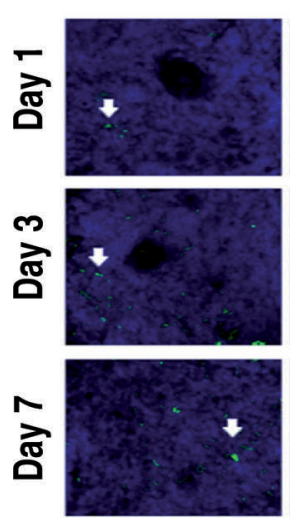

Mild
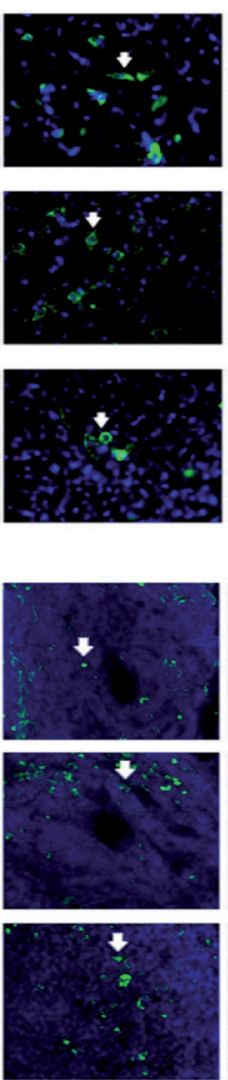

Severe
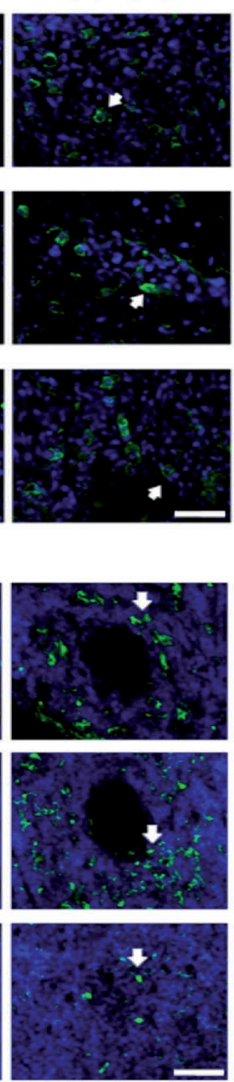

C

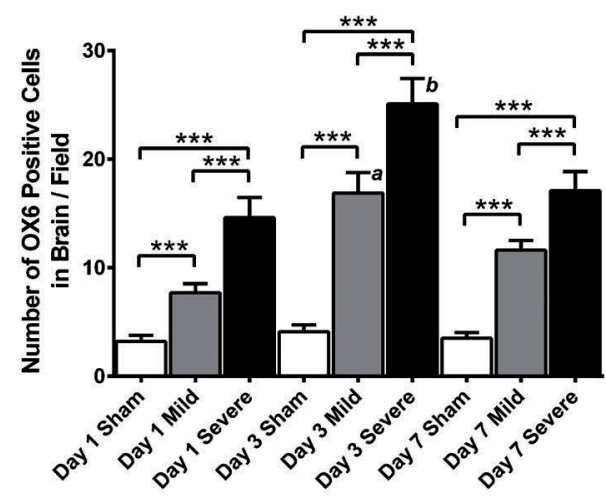

D

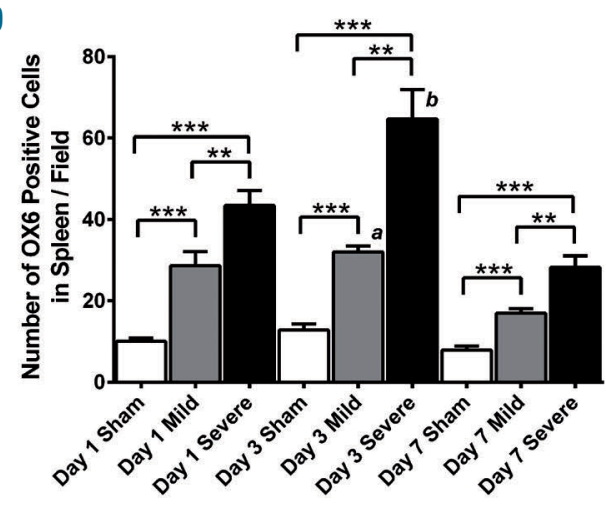

Figure 4. Immunofluorescent staining of inflammatory cells. (A and B) OX6-stained microglia/macrophages were frequently found in the periphery of the site of stem cell injection site in the brain (A) and around the blood vessels in the spleen (B), and the number of OX6-positive cells in the stroke groups was higher than in the sham-treated groups. Nuclei were stained with DAPI. Arrow heads indicate OX6-positive cells. Scale bars = $100 \mu \mathrm{m}$. Green: OX6; blue: DAPI. (C and D) In quantitative analyses of the brain $(C)$ and the spleen (D), the stroke groups exhibited a higher number of OX6-positive cells than did the sham-treated group ( $* * P<0.01$ ). Significance bars: $* * P<0.01$; $* * * P<0.001$. (C) a: The group with mild stroke had significantly more OX6-positive cells in the brain on day 3 than on other days $(P<0.01)$; $b$ : the group with severe stroke had significantly more 0x6-positive cells in the brain on day 3 than on other days $(P<0.001)$. (D) a: The group with mild stroke had significantly more OX6-positive cells in the spleen on day 3 than on other days $(\mathrm{P}<0.01)$; $b$ : the group with severe stroke had significantly more OX6-positive cells in the spleen on day 3 than on other days $(P<0.001)$. 
lymphatic vessels were capable of carrying hBMSC to the spleen. Indeed, the most novel finding in this study is the discovery that hBMSC were able to migrate directly to the spleen via lymphatic vessels; immunofluorescence analysis of the brain and spleen revealed that hBMSC were found within these vessels.

Microglial cells - the resident macrophages of the brain - are activated rapidly in response to brain injury. ${ }^{42,43}$ Experimental data have shown that resident microglia are activated within minutes of the onset of ischemia and produce a plethora of proinflammatory mediators including interleukin-1 $\beta$ and TNF- $\alpha$, which exacerbate tissue damage $^{44}$ yet may also protect the brain against ischemic and excitotoxic injury. ${ }^{45,46}$ Post-ischemic microglial proliferation peaks at 48-72 $\mathrm{h}$ after the onset of cerebral ischemia and may last for several weeks after the initial injury. ${ }^{47,48}$

Given the preferential migration of hBMSC toward microglia under inflammatory conditions seen in vitro, it was hypothesized that the microglia may play a key role in facilitating the transplanted stem cells' journey into the spleen. Elevated levels of OX6-positive cells were found in both the brain and spleen after stroke, especially in animals with severe stroke. The density of inflammatory cells in the spleen was much higher than in the brain. Greater stroke severity was correlated with a rise in OX6positive cells and their increased co-localization with
LYVE1 in both the brain and the spleen. The data reveal a more robust migration of OX6-positive cells from the brain to the spleen in response to a more severe stroke. Thus, the present results suggest that elevated inflammation accompanying more severe strokes may also account for the greater successful migration of transplanted stem cells to the spleen. Hence, it is likely that hBMSC possess biodistribution patterns in which they localize around major sites of inflammation, such as the infarct area in the brain and the white pulp in the spleen, which contains numerous inflammatory cells and lymphatic cells that could attract these hBMSC. ${ }^{49}$ Indeed, high concentrations of hBMSC were deposited in the white pulp of the spleen. We advance the premise that tracking the biodistribution of intracerebrally transplanted hBMSC beyond the spleen, and to other peripheral organs (e.g., thymus) which also mount strong inflammation in response to central nervous system insults, including stroke, represents an innovative paradigm-shifting future investigation (e.g., for brain disorders with robust peripheral pathological components, thereby requiring peripheral sequestration of systemic inflammation).

Normally, the BBB functions as an impermeable barricade to defend against detrimental pathogens and substances. However, inflammation induced by an ischemic stroke can lead to impaired endothelial activity and com-
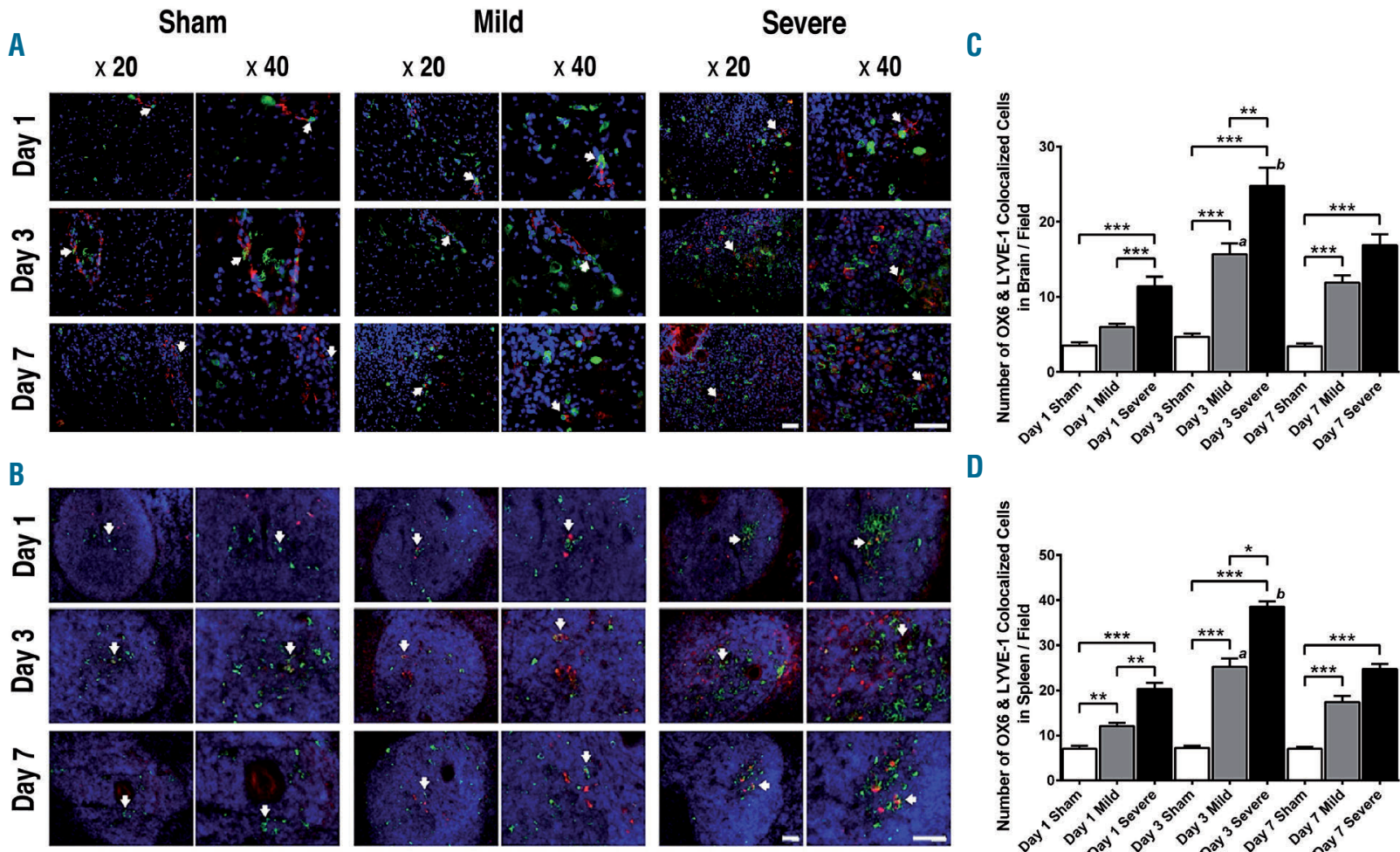

D

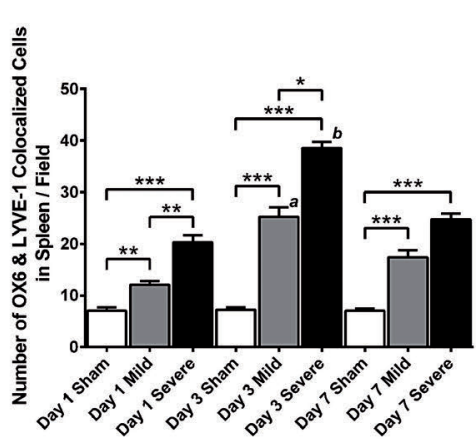

Figure 5. Localization of OX6-positive cells near or within lymphatic vessels in the brain and spleen. (A and B) Staining with OX6, lymphatic vessel endothelial hyaluronan receptor-1 (LYVE-1), and DAPI, was performed to visualize microglia/macrophages, lymphatic endothelial cells, and nuclei, respectively, in the brain (A) and spleen (B). Arrow heads indicate co-localization of OX6-positive and LYVE-1-positive cells and show that microglia/macrophages localized near or within lymphatic vessels in the brain and spleen. Pictures taken under 20x and 40x magnification. Scale bars = 100 um. Red: LYVE-1; green: OX6; blue: DAPI. (A) Images were taken close to the dural sinuses in the brain. (B) Images were taken near the gate of the spleen, close to the white pulp in the spleen. (C and D) In quantitative analyses of the brain $(C)$ and the spleen $(D)$, the stroke groups exhibited higher numbers of co-localized cells than did the sham-treated group ( $* * P<0.01)$. Significance bars: $\star P<0.05 ; * * P<0.01 ; * * * P<0.001$. (C) a: The group with mild stroke had significantly more co-localization in the brain on day 3 than on other days $(P<0.05)$; b: the group with severe stroke had significantly more co-localized cells in the brain on day 3 than on other days $(P<0.01)$. (D) a: The group with mild stroke had significantly more co-localization in the spleen on day 3 than on other days $(P<0.05)$; $b$ : the group with severe stroke had significantly more co-localized cells in the spleen on day 3 than on other days $(P<0.01)$. 
promise BBB function, enabling cells such as macrophages to pass the barrier.7 Thus, while our data demonstrate that hBMSC likely utilized lymphatic vessels to migrate to the spleen, it is also possible that hBMSC in the brain were able to cross the now permeable $\mathrm{BBB}$ and enter the bloodstream, enabling them to migrate to the spleen via systemic circulatory pathways. As the groups with severe stroke had more severe inflammation, this may have resulted in more damage to the $\mathrm{BBB}$, and could also explain why more transplanted cells migrated from the brain to the periphery (i.e., spleen) in these groups. Future studies could further probe this concept by measuring stem cell levels in the blood, as well as graft deposition in other peripheral organs.

The in vitro results revealed an increase in hBMSC migration toward lymphatic endothelial cells, microglia, or a combination of both when treated with TNF- $\alpha$. The increasing number of migratory hBMSC was dependent on the dose of TNF- $\alpha$ in every experimental group. Interestingly, the greatest migratory activity was seen in the cultures of TNF- $\alpha$-treated microglia cells alone versus either lymphatic endothelial cells or the co-culture of both cell types with TNF- $\alpha$. Since bEnd. 3 cells are a brain endothelioma cell line, it is possible that the hBMSC also migrated to brain parenchymal endothelial cells, in addition to LYVE-1 lymphatic endothelial cells. However, adding TNF- $\alpha$ increases the ability of bEnd. 3 cells to form LYVE-1-expressing lymphatic tubes. ${ }^{50}$ Thus, it is likely that in our cell migration assays involving TNF- $\alpha$, the majority of hBMSC migrated to the LYVE-1 lymphatic endothelial cells, which were likely present in a higher proportion.

Prior studies have demonstrated that the injection of
A

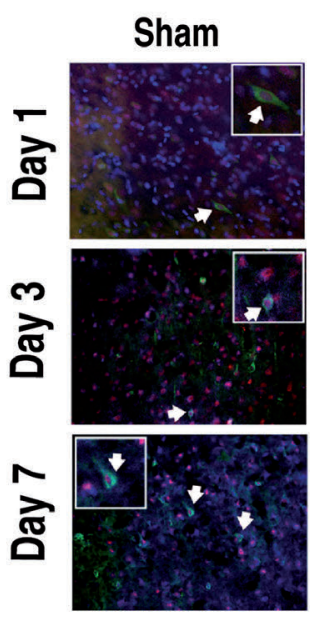

B

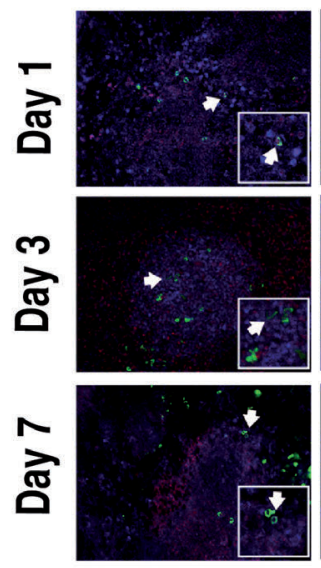

Mild
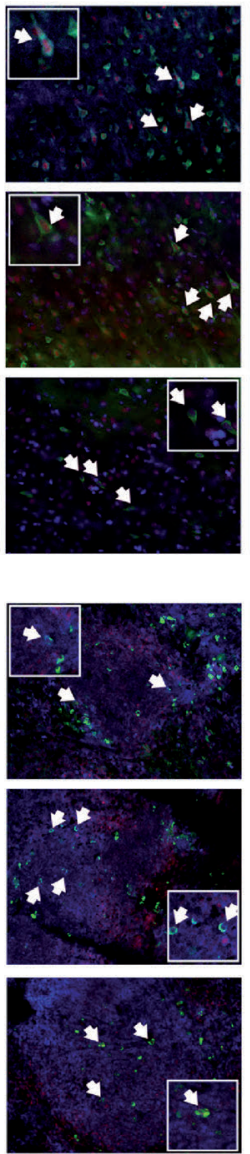

Severe
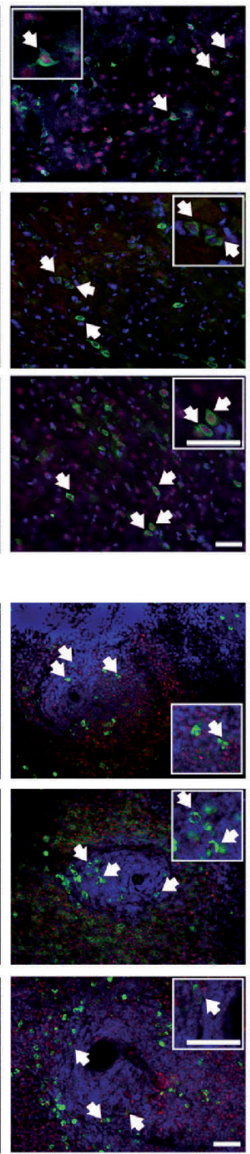

C

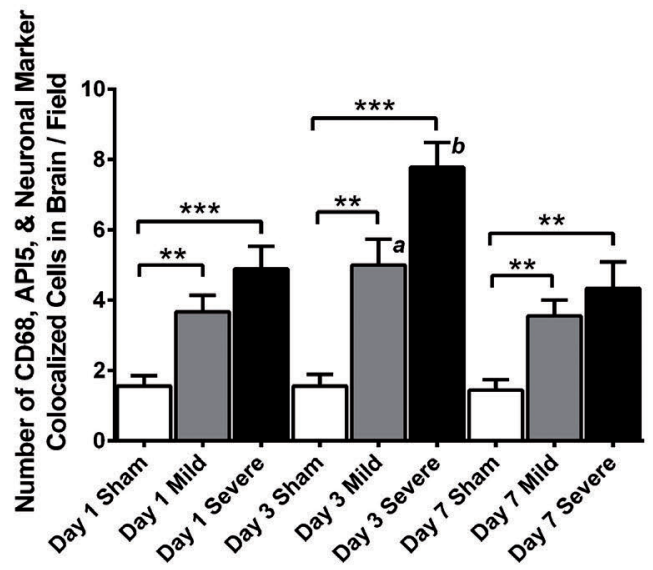

D

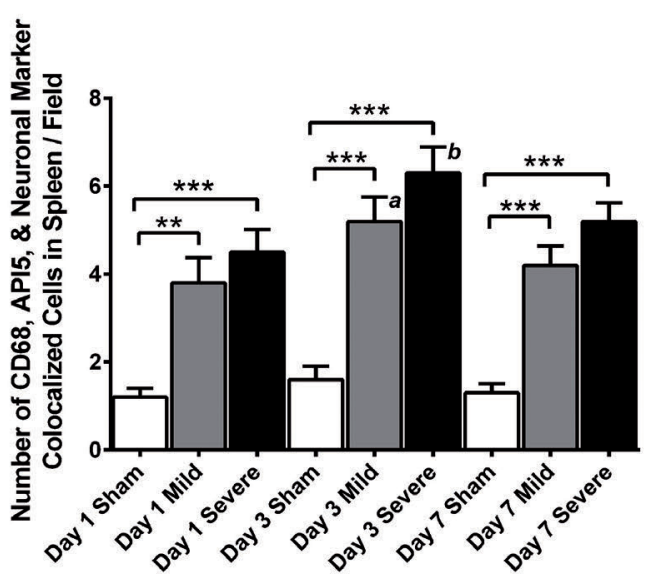

Figure 6. Transplanted human bone marrow mesenchymal stromal cells phagocytose ischemic neurons in the brain and transport them to the spleen. (A and $B$ ) Triple immunofluorescent staining for human specific phagocytic marker CD68 (CD68), anti-apoptosis inhibitor 5 (API5), and anti-160kD neurofilament medium antibody-rat specific neuronal marker (neuronal marker) was performed in the brain (A) and spleen (B). Groups with mild and severe stroke demonstrated higher frequencies of staining overlap compared to the sham-treated group. Arrow heads indicate co-localization of CD68-positive, anti-apoptosis inhibitor 5-positive, and neuronal marker-positive cells. The small boxes show 40x magnification. Scale bars $=100 \mu \mathrm{m}$. Red: anti-apoptosis inhibitor 5; green: CD68; blue: neuronal marker. (C and D) Quantitative analyses of the estimated number of co-localized cells exhibiting overlap for all three stains in the brain (C) and in the spleen (D) of stroke and sham-treated animals. Significance bars: $* * P<0.01 ; * * * P<0.001$. Groups with mild and severe stroke displayed significantly higher quantities of co-localization in the brain and spleen relative to the sham-treated group on all days that measurements were made $(* * P<0.01)$. Co-localization levels peaked on day 3 in all organs in the groups with mild and severe stroke, especially in the groups with severe stroke $(* * P<0.01)$. (C) a: The group with mild stroke had significantly more co-localized cells in the brain on day 3 than on other days $(P<0.05)$; $b$ : the group with severe stroke had significantly more co-localized cells in the brain on day 3 than on other days $(P<0.01)$. (D) a: The group with mild stroke had significantly more co-localized cells in the spleen on day 3 than on other days $(P<0.05) ; b$ : the group with severe stroke had significantly more co-localized cells in the spleen on day 3 than on other days $(P<0.05)$. 
hBMSC into immunocompetent rats ${ }^{19}$ has neuroprotective benefits similar to those obtained by transplanting murine-derived stem cells into rats. ${ }^{51}$ hBMSC have advantages over other cell types, such as circumventing ethical concerns and host rejection of transplanted stem cell grafts, enabling allogeneic transplantation. ${ }^{52}$ Moreover, utilizing human-derived cells in preclinical studies may be more clinically relevant, as future cell transplantation therapies in the clinic will likely employ human-derived stem cells to treat neurological disorders. Despite these logisti-
A

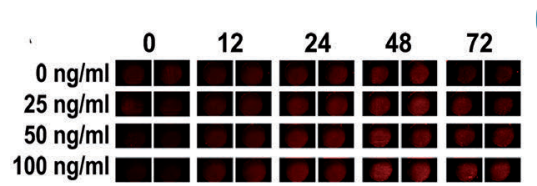

\section{C}

E

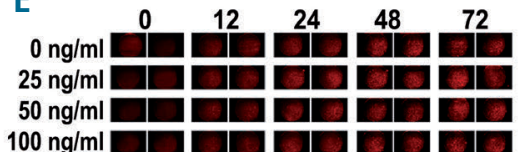

F

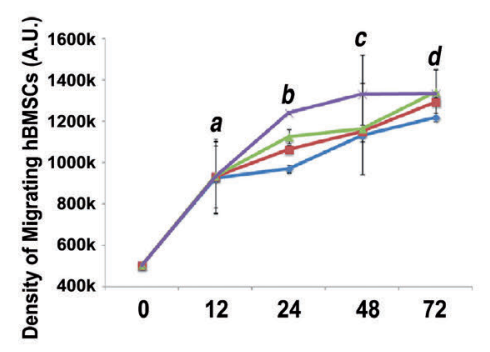

G

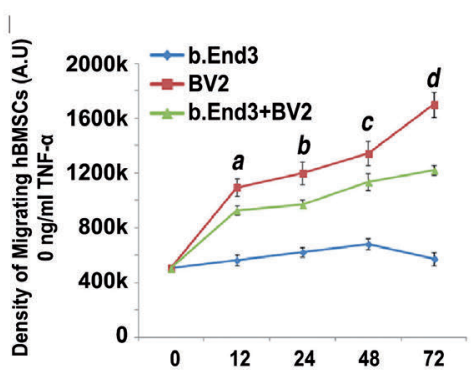

I

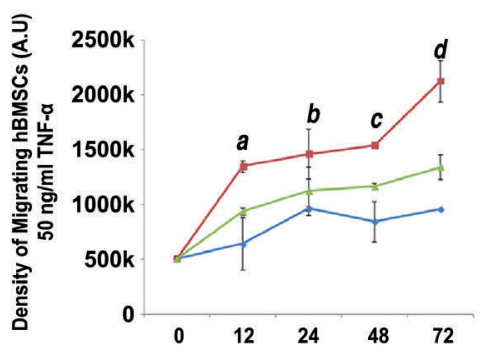

H

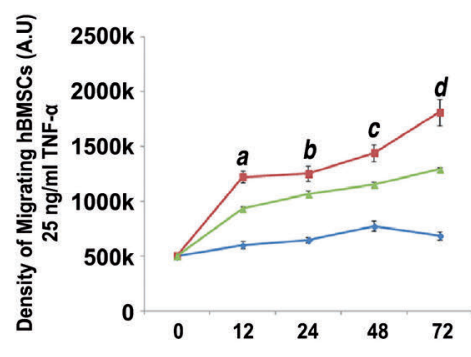

$J$

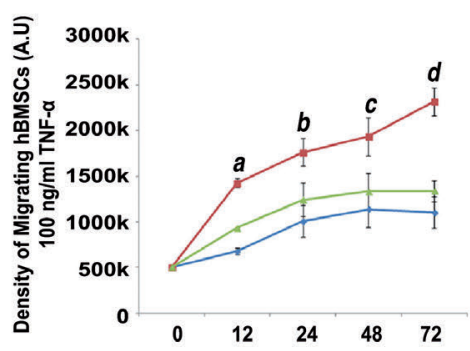

Figure 7. Migration of human bone marrow mesenchymal stromal cells to bEnd.3, BV2, and bEnd.3+BV2 cells in cell migration assays. (A-F) Human bone marrow mesenchymal stromal cells (hBMSC) migrate to three experimental groups: lymphoid endothelial cells (bEnd.3) (A and B), microglia (BV2) (C and D), and a combination of BV2+bEnd. 3 cells ( $E$ and F). Cell density was measured over time $(0-72 \mathrm{~h})$ and in response to varying doses of tumor necrosis factor alpha (TNF- $\alpha$ : 0 ng/mL, $25 \mathrm{ng} / \mathrm{mL}, 50 \mathrm{ng} / \mathrm{mL}$, or $100 \mathrm{ng} / \mathrm{mL}$ ). Compared with the non-treated control group, TNF- $\alpha$ significantly increased the number of migrating hBMSC, indicating that TNF- $\alpha$ plays a critical role in the migration of hBMSC in vitro. (A, C, E) Visualization of the density of hBMSC migrating to bEnd.3 (A), BV2 (C), and bEnd.3+BV2 (E) over time and in response to increasing TNF- $\alpha$ doses. (B, D, F) Quantitative analyses of the density of hBMSC migrating to bEnd.3 (B), BV2 (D), and bEnd.3+BV2 (F) over time and in response to increasing TNF- $\alpha$ doses. Significance values: (A) a: $0 \mathrm{ng} / \mathrm{mL} v \mathrm{ss} .25 \mathrm{ng} / \mathrm{mL}(P<0.05) ; 0 \mathrm{ng} / \mathrm{mL} v \mathrm{vs} .50 \mathrm{ng} / \mathrm{mL}(P<0.05)$. b: $0 \mathrm{ng} / \mathrm{mL}$ vs. $25 \mathrm{ng} / \mathrm{mL}(P<0.05) ; 0 \mathrm{ng} / \mathrm{mL}$ vs. $50 \mathrm{ng} / \mathrm{mL}(P<0.05)$. c: $50 \mathrm{ng} / \mathrm{mL}$ vs. $100 \mathrm{ng} / \mathrm{mL}(P<0.05)$. d: $25 \mathrm{ng} / \mathrm{mL}$ vs. $50 \mathrm{ng} / \mathrm{mL}(P<0.01) ; 50 \mathrm{ng} / \mathrm{mL}$ vs. $100 \mathrm{ng} / \mathrm{mL}(P<0.01)$. (B) a: $0 \mathrm{ng} / \mathrm{mL}$ vs. $50 \mathrm{ng} / \mathrm{mL}(P<0.05) ; 25 \mathrm{ng} / \mathrm{mL}$ vs. $100 \mathrm{ng} / \mathrm{mL}(P<0.05)$. b: $25 \mathrm{ng} / \mathrm{mL}$ vs. $100 \mathrm{ng} / \mathrm{mL}(P<0.05) ; 50 \mathrm{ng} / \mathrm{mL}$ vs. $100 \mathrm{ng} / \mathrm{mL}(P<0.05)$. C: $0 \mathrm{ng} / \mathrm{mL}$ vs. $50 \mathrm{ng} / \mathrm{mL}$ ( $P<0.05) ; 25 \mathrm{ng} / \mathrm{mL}$ vs. $50 \mathrm{ng} / \mathrm{mL}(P<0.05) ; 25 \mathrm{ng} / \mathrm{mL}$ vs. $100 \mathrm{ng} / \mathrm{mL}(P<0.05) . \mathrm{d}: 25 \mathrm{ng} / \mathrm{mL}$ vs. $100 \mathrm{ng} / \mathrm{mL}(P<0.05) .(C)$ a: $25 \mathrm{ng} / \mathrm{mL}$ vs. $100 \mathrm{ng} / \mathrm{mL}$ (P<0.05). b: $0 \mathrm{ng} / \mathrm{mL}$ vs. $100 \mathrm{ng} / \mathrm{mL}(P<0.05) ; 25 \mathrm{ng} / \mathrm{mL}$ vs. $50 \mathrm{ng} / \mathrm{mL}(P<0.05)$. c: $0 \mathrm{ng} / \mathrm{mL}$ vs. $50 \mathrm{ng} / \mathrm{mL}(P<0.05) ; 0 \mathrm{ng} / \mathrm{mL}$ vs. $100 \mathrm{ng} / \mathrm{mL}(P<0.05) ; 25 \mathrm{ng} / \mathrm{mL}$ vs. $50 \mathrm{ng} / \mathrm{mL}(P<0.05)$. d: $0 \mathrm{ng} / \mathrm{mL}$ vs. $50 \mathrm{ng} / \mathrm{mL}(P<0.01) ; 25 \mathrm{ng} / \mathrm{mL}$ vs. $50 \mathrm{ng} / \mathrm{mL}(P<0.01) ; 50 \mathrm{ng} / \mathrm{mL}$ vs. $100 \mathrm{ng} / \mathrm{mL}(P<0.01)$. (G-J) hBMSC preferentially migrate to BV2 microglial cells in cell migration assays. Quantitative comparisons between the amount of hBMSC migrating to BV2, bEnd.3, and BV2+bEnd.3 over time and within specific doses of TNF- $\alpha[0 \mathrm{ng} / \mathrm{mL}(\mathrm{G}), 25 \mathrm{ng} / \mathrm{mL}(\mathrm{H}), 50 \mathrm{ng} / \mathrm{mL}(\mathrm{I})$, and $100 \mathrm{ng} / \mathrm{mL}(\mathrm{J})]$. The number of migrating hBMSC was highest for BV2 for all doses of TNF- $\alpha$, indicating how hBMSC preferentially migrate to BV2. The density of migrating hBMSC was significantly higher for BV2 than for bEnd.3 and BV2+bEnd.3 for all TNF- $\alpha$ doses. There were significantly more migrating hBMSC for bEnd.3+BV2 than for bEnd.3 for all TNF- $\alpha$ doses. Significance values: (G) a: $b$.End3 vs. b. End3+BV2 $(P<0.05)$. b: BV2 vs. b.End3+BV2 $(P<0.05)$. c: BV2 vs. b.End3+BV2 $(P<0.05)$. d: BV2 vs. b.End3+BV2 $(P<0.05)$. (H) a: b.End3 vs. BV2 $(P<0.001)$; b.End3 vs. b.End3+BV2 ( $P<0.001)$; BV2 vs. b.End3+BV2 ( $P<0.001)$. b: BV2 vs. b.End3+BV2 ( $P<0.05)$. c: BV2 vs. b.End3+BV2 $(P<0.05)$. d: BV2 vs. b.End3+BV2 ( $<<0.05)$. (I) a: b. End3 vs. BV2 ( $P<0.001)$; b. End3 vs. b.End3+BV2 ( $P<0.001)$; BV2 vs. b.End3+BV2 $(P<0.001)$. b: b. End3 vs. BV2 ( $P<0.01)$; b.End3 vs. b.End3+BV2 $(P<0.01)$; BV2 vs. b.End3+BV2 ( $P<0.01)$. c: BV2 vs. b.End3+BV2 ( $P<0.01)$. d: b. End3 vs. b.End3+BV2 $(P<0.05)$. (J) a: b. End3 vs. b.End3+BV2 (P<0.05). b: b.End3 vs. BV2 (P<0.001); b.End3 vs. b.End3+BV2 ( $P<0.001)$; BV2 vs. b.End3+BV2 $(P<0.001)$. c: b.End3 vs. b.End3+BV2 $(P<0.01)$. d: b. End3 vs. b.End3+BV2 (P<0.05). 
cal and translational advantages of using human cells in an immunocompetent rat model, we recognize the possibility that the present results may be due to the phenomenal cross-species immunomodulation platform created by this model. We also concede that a same-species transplant paradigm may need to confirm the present observation of inflammation- and lymphatic-mediated brain-to-spleen migration of grafted stem cells. Notwithstanding this limitation, we submit that the current xeno-transplantation paradigm exaggerates the role of inflammation and/or the immune system on the lymphatic systems and stem cell fate, i.e., migration. As inhibiting lymphatic vessel contraction is associated with immunosuppression, it is possible that suppressing the immune system in an immunosuppressed rat model would hinder the lymphatic system's ability to coordinate lymph flow and thus obstruct the migration of hBMSC from the brain to the spleen. ${ }^{53}$

Despite being a subject of debate, the optimal time point for the application of stem cells in the clinical setting exists, both in terms of stem cell tropism toward the brain and overall therapeutic effectiveness. The undecided nature of this ideal time point is, however, a major hurdle to progress in stem cell therapies in stroke. In our study, rats were reperfused 1 hour after the middle cerebral artery occlusion surgery and received hBMSC at this point. Preclinical studies reveal that at this acute phase of stroke, the levels of chemokines and trophic factors increase markedly in the infarcted brain and subsequently decrease over time. ${ }^{54}$ This large release of inflammatory factors, oxygen free radicals, and excitatory neurotransmission toxins (e.g., glutamate and glycine) may pose a threat to the survival of the recently transplanted stem cells. The application of stem cells during the acute phase of stroke may be necessary to offer a range of paracrine and immunomodulatory effects significant enough to reduce secondary injury processes and stimulate brain repair after stroke. ${ }^{55}$ Admittedly, 1 hour after a stroke is not the most clinically feasible time. However, later deliveries are plagued by the existence of a nonconducive microenvironment after cerebral infarction which may interfere with the transplanted stem cells' ability to survive. Thus, it is important to determine the ideal, realistic time point, when the transplanted cells can not only survive in the infarcted area and salvage affected brain tissue, but also, as this study shows, effectively modulate peripheral immune responses to reduce the harmful inflammation. This requires more in-depth research. Here, we demonstrated a phenomenon whereby intracerebrally transplanted stem cells can migrate to the spleen via the lymphatic system, propelled by inflammatory signals. However, characterizing the function of the stem cells once within the spleen, how this in turn affects global inflammatory factors, and the ultimate effects on brain health, are mechanisms which require deeper study.

This study supports an alternative mechanism essential to cell therapy for stroke, advancing the notion that while the brain is the ultimate therapeutic target of stem cells, achieving functional recovery may occur as a systematic event. The intuitive mechanism whereby stem cells replace dead and dying neurons, integrating into functional circuits, only occurs to a slight extent. ${ }^{56}$ Thus, a complete explanation for the functional recovery associated with stem cell therapies in stroke requires an understanding of the non-cell replacement mechanisms of stem cells. Intracerebrally transplanted hBMSC phagocytose apoptotic neurons, depart from the ischemic tissue of the brain, and travel toward the spleen via lymphatic vessels. From

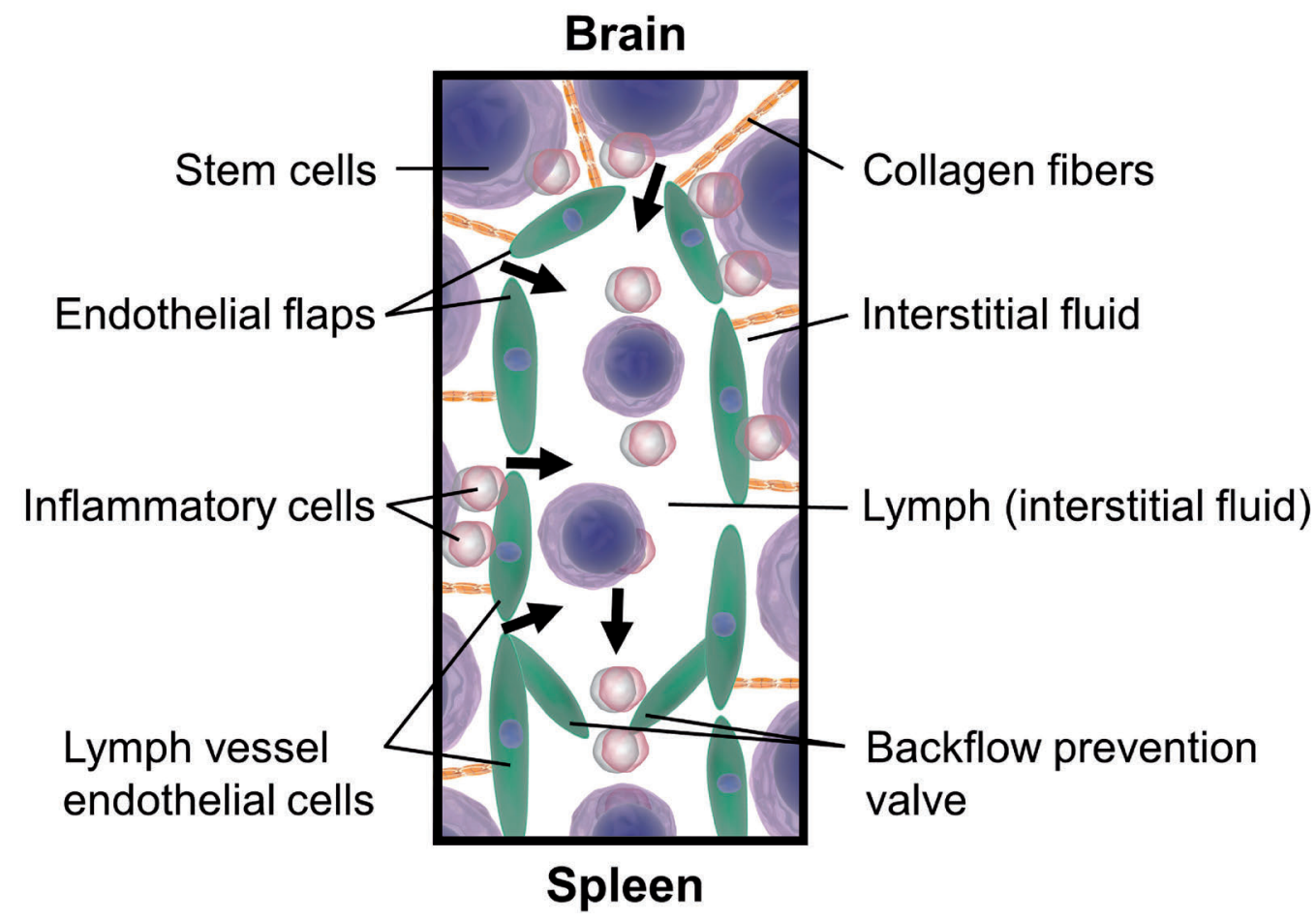

Figure 8. Illustration demonstrating how stem cells migrate from the brain to the spleen via lymphatic vessels and with guidance from inflammatory cells. Stem cells engrafted in the brain enter lymphatic vessels in the brain and inflammatory cues direct the transplanted stem cells toward the spleen. 
the standpoint of basic science, the observation of transplanted human stem cells within the lymphatic vessels and adjacent to inflammatory cells in the brain, but surprisingly also in the spleen, reveals for the first time the migration of intracerebrally infused stem cells to the periphery. From a translational research view, the visualization of transplanted stem cells within lymphatic vessels and CD68-positive stem cells phagocytosing apoptotic neurons in the brain and spleen may correspond to a novel clean-up machinery of stem cells designed to dampen the stroke brain's overload of cell death components and signals, scuttling them from the central nervous system to the periphery. Altogether, our observations indicate that stem cells are capable of phagocytic activity centrally and peripherally, likely designed to sequester and remove inflammatory cells and dying neurons from the brain and dump them in the periphery, and suggest a therapeutic mechanism involving central and peripheral sequestration of stroke inflammation. Moreover, the observed hBMSC migration patterns indicate the central role of the spleen in stroke pathology and reaffirm the importance of inflammatory signaling in stem cell migration. This study resolves the apparent paradox of robust functional recovery seen after stem cell transplantation in stroke despite minimal graft survival rates.

In summary, we demonstrate here that intracerebrally transplanted stem cells exhibit the ability to migrate from the brain parenchyma to the spleen via lymphatic vessels, led by inflammatory signals. Describing the migratory patterns and biodistribution of stem cells following transplantation furthers our understanding of how these cells offer their therapeutic effects as well as enhancing our knowledge of the spleen and lymphatic system's involvement in stroke pathology.

\section{Acknowledgments}

This work was supported by NIH grants 5R01-NS09096201 to CVB and NIH 1RONS102395-0 to CVB.

\section{References}

1. Kim AS, Cahill E, Cheng NT. Global stroke belt: geographic variation in stroke burden worldwide. Stroke. 2015;46(12):3564-3570.

2. Gopurappilly R, Pal R, Mamidi MK, Dey S, Bhonde R, Das AK. Stem cells in stroke repair: current success and future prospects. CNS Neurol Disord Drug Targets. 2011;10(6):741-756.

3. Liska MG, Crowley MG, Borlongan CV. Regulated and unregulated clinical trials of stem cell therapies for stroke. Transl Stroke Res. 2017;8(2):93-103.

4. Moskowitz MA, Lo EH, Iadecola C. The science of stroke: mechanisms in search of treatments. Neuron. 2010;67(2):181-198.

5. Macrez R, Ali C, Toutirais O, et al. Stroke and the immune system: from pathophysiology to new therapeutic strategies. Lancet Neurol. 2011;10(5):471-480.

6. Yong VW, Rivest S. Taking advantage of the systemic immune system to cure brain diseases. Neuron. 2009;64(1):55-60.

7. Jin R, Yang G, Li G. Inflammatory mechanisms in ischemic stroke: role of inflammatory cells. J Leukoc Biol. 2010;87(5):779-789.

8. Denes A, Ferenczi S, Kovacs KJ. Systemic inflammatory challenges compromise survival after experimental stroke via augmenting brain inflammation, blood-brain barrier damage and brain oedema independently of infarct size. J Neuroinflammation. 2011; 8:164.

9. Kassner A, Merali Z. Assessment of bloodbrain barrier disruption in stroke. Stroke. 2015;46(11):3310-3315

10. McColl BW, Rothwell NJ, Allan SM. Systemic inflammation alters the kinetics of cerebrovascular tight junction disruption after experimental stroke in mice. J Neurosci. 2008;28(38):9451-9462.

11. Yepes M, Brown SA, Moore EG, Smith EP, Lawrence DA, Winkles JA. A soluble fn14-fc decoy receptor reduces infarct volume in a murine model of cerebral ischemia. Am J Pathol. 2005;166(2):511-520.

12. Vendrame M, Gemma C, Pennypacker KR, et al. Cord blood rescues stroke-induced changes in splenocyte phenotype and function. Exp Neurol. 2006;199(1):191-200

13. Crowley MG, Liska MG, Borlongan CV.
Stem cell therapy for sequestering neuroinflammation in traumatic brain injury: an update on exosome-targeting to the spleen. J Neurosurg Sci. 2017;61(3):291-302

14. Vahidy FS, Parsha KN, Rahbar MH, et al. Acute splenic responses in patients with ischemic stroke and intracerebral hemorrhage. J Cereb Blood Flow Metab. 2016;36(6):1012-1021.

15. Swirski FK, Nahrendorf M, Etzrodt M, et al. Identification of splenic reservoir monocytes and their deployment to inflammatory sites. Science. 2009;325(5940):612-616.

16. Ajmo CT Jr, Vernon DO, Collier L, et al. The spleen contributes to stroke-induced neurodegeneration. J Neurosci Res. 2008;86(10): 2227-2234.

17. Chiba T, Umegaki K. Pivotal roles of monocytes/macrophages in stroke. Mediators Inflamm. 2013;2013:759103.

18. Offner H, Subramanian S, Parker SM, Afentoulis ME, Vandenbark AA, Hurn PD. Experimental stroke induces massive, rapid activation of the peripheral immune system. J Cereb Blood Flow Metab. 2006;26(5):654665.

19. Acosta SA, Tajiri N, Hoover J, Kaneko Y, Borlongan CV. Intravenous bone marrow stem cell grafts preferentially migrate to spleen and abrogate chronic inflammation in stroke. Stroke. 2015;46(9):2616-2627.

20. Mashkouri S, Crowley MG, Liska MG, Corey S, Borlongan CV. Utilizing pharmacotherapy and mesenchymal stem cell therapy to reduce inflammation following traumatic brain injury. Neural Regen Res. 2016;11(9):1379-1384.

21. Tajiri N, Acosta SA, Shahaduzzaman M, et al. Intravenous transplants of human adipose-derived stem cell protect the brain from traumatic brain injury-induced neurodegeneration and motor and cognitive impairments: cell graft biodistribution and soluble factors in young and aged rats. J Neurosci. 2014;34(1):313-326.

22. Louveau A, Smirnov I, Keyes TJ, et al. Structural and functional features of central nervous system lymphatic vessels. Nature. 2015;523(7560):337-341.

23. Ishikawa $\mathrm{H}$, Tajiri $\mathrm{N}$, Shinozuka $\mathrm{K}$, et al. Vasculogenesis in experimental stroke after human cerebral endothelial cell transplanta- tion. Stroke. 2013;44(12):3473-3481.

24. Yu SJ, Soncini M, Kaneko Y, Hess DC, Parolini O, Borlongan CV. Amnion: a potent graft source for cell therapy in stroke. Cell Transplant. 2009;18(2):111-118.

25. Trakarnsanga K, Griffiths RE, Wilson MC, et al. An immortalized adult human erythroid line facilitates sustainable and scalable generation of functional red cells. Nat Commun 2017;8:14750

26. Tajiri N, Quach D, Kaneko Y, et al. Behavioral and histopathological assessment of adult ischemic rat brains after intracerebral transplantation of NSI-566RSC cell lines. PLoS One. 2014;9(3):e91408.

27. Glover LE, Tajiri N, Lau T, Kaneko Y, van Loveren $\mathrm{H}$, Borlongan CV. Immediate, but not delayed, microsurgical skull reconstruction exacerbates brain damage in experimental traumatic brain injury model. PLoS One. 2012;7(3):e33646.

28. Dantzer R, O'Connor JC, Freund GG, Johnson RW, Kelley KW. From inflammation to sickness and depression: when the immune system subjugates the brain. Nat Rev Neurosci. 2008;9(1):46-56.

29. Qureshi IA, Mehler MF. Towards a 'system$s$-level understanding of the nervous system and its disorders. Trends Neurosci. 2013;36(11):674-684.

30. Vendrame M, Cassady J, Newcomb J, et al. Infusion of human umbilical cord blood cells in a rat model of stroke dose-dependently rescues behavioral deficits and reduces infarct volume. Stroke. 2004;35(10):23902395.

31. Schwarting S, Litwak S, Hao W, Bahr M, Weise J, Neumann H. Hematopoietic stem cells reduce postischemic inflammation and ameliorate ischemic brain injury. Stroke. 2008;39(10):2867-2875

32. Barbosa da Fonseca LM, Gutfilen B, Rosado de Castro $\mathrm{PH}$, et al. Migration and homing of bone-marrow mononuclear cells in chronic ischemic stroke after intra-arterial injection. Exp Neurol. 2010;221(1):122-128.

33. Yang B, Hamilton JA, Valenzuela KS, et al Multipotent adult progenitor cells enhance recovery after stroke by modulating the immune response from the spleen. Stem Cells. 2017;35(5):1290-1302

34. Koh HS, Chang CY, Jeon SB, et al. The hif- 
1/glial tim-3 axis controls inflammationassociated brain damage under hypoxia. Nat Commun. 2015;6:6340.

35. Li D, Lang W, Zhou C, et al. Upregulation of microglial zeb1 ameliorates brain damage after acute ischemic stroke. Cell Rep. 2018;22(13):3574-3586.

36. Barbash IM, Chouraqui P, Baron J, et al. Systemic delivery of bone marrow-derived mesenchymal stem cells to the infarcted myocardium: feasibility, cell migration, and body distribution. Circulation. 2003;108(7): 863-868.

37. Chamberlain G, Fox J, Ashton B, Middleton I. Concise review: mesenchymal stem cells: Their phenotype, differentiation capacity, immunological features, and potential for homing. Stem Cells. 2007;25(11):27392749.

38. Karp JM, Leng Teo GS. Mesenchymal stem cell homing: the devil is in the details. Cell Stem Cell. 2009;4(3):206-216.

39. Ponte AL, Marais E, Gallay N, et al. The in vitro migration capacity of human bone marrow mesenchymal stem cells: comparison of chemokine and growth factor chemotactic activities. Stem Cells. 2007;25 (7):1737-1745.

40. Takatera A, Takeuchi A, Saiki K, Morioka I, Yokoyama N, Matsuo M. Blood lysophosphatidylcholine (LPC) levels and characteristic molecular species in neonates: prolonged low blood LPC levels in very low birth weight infants. Pediatr Res. 2007;62(4):477482.

41. Girard JP, Moussion C, Forster R. Hevs, lym- phatics and homeostatic immune cell trafficking in lymph nodes. Nat Rev Immunol. 2012;12(11):762-773.

42. Aloisi F. Immune function of microglia. Glia. 2001;36(2):165-179.

43. Nakajima K, Kohsaka S. Microglia: activation and their significance in the central nervous system. J Biochem. 2001;130 (2):169-175.

44. Barone FC, Arvin B, White RF, et al. Tumor necrosis factor-alpha. A mediator of focal ischemic brain injury. Stroke. 1997;28(6): 1233-1244.

45. Hallenbeck JM. The many faces of tumor necrosis factor in stroke. Nat Med. 2002;8(12):1363-1368.

46. Raivich G, Bohatschek M, Kloss CU, Werner A, Jones LL, Kreutzberg GW. Neuroglial activation repertoire in the injured brain: graded response, molecular mechanisms and cues to physiological function. Brain Res Brain Res Rev. 1999;30(1):77-105

47. Denes A, Vidyasagar R, Feng J, et al. Proliferating resident microglia after focal cerebral ischaemia in mice. J Cereb Blood Flow Metab. 2007;27(12):1941-1953.

48. Lalancette-Hebert M, Gowing G, Simard A Weng YC, Kriz J. Selective ablation of proliferating microglial cells exacerbates ischemic injury in the brain. J Neurosci. 2007;27(10): 2596-2605.

49. Aoshi T, Zinselmeyer BH, Konjufca V, et al Bacterial entry to the splenic white pulp initiates antigen presentation to CD8+ T cells. Immunity. 2008;29(3):476-486.

50. Yuen D, Leu R, Tse J, Wang S, Chen LL,
Chen L. Novel characterization of bEnd.3 cells that express lymphatic vessel endothelial hyaluronan receptor-1. Lymphology. 2014;47(2):73-81.

51. Wei L, Fraser JL, Lu ZY, Hu X, Yu SP Transplantation of hypoxia preconditioned bone marrow mesenchymal stem cells enhances angiogenesis and neurogenesis after cerebral ischemia in rats. Neurobio Dis. 2012;46(3):635-645

52. Mitkari B, Nitzsche F, Kerkela E, et al Human bone marrow mesenchymal stem/stromal cells produce efficient localization in the brain and enhanced angiogenesis after intra-arterial delivery in rats with cerebral ischemia, but this is not translated to behavioral recovery. Behav Brain Res. 2014:259:50-59.

53. Liao S, Cheng G, Conner DA, et al. Impaired lymphatic contraction associated with immunosuppression. Proc Natl Acad Sci U S A. 2011;108(46):18784-18789.

54. Hill WD, Hess DC, Martin-Studdard A, et al Sdf-1 (CXCL12) is upregulated in the ischemic penumbra following stroke: association with bone marrow cell homing to injury. J Neuropathol Exp Neurol. 2004;63(1):84-96

55. Savitz SI. Developing cellular therapies for stroke. Stroke. 2015;46(7):2026-2031.

56. Stonesifer C, Corey S, Ghanekar S, Diamandis Z, Acosta SA, Borlongan CV. Stem cell therapy for abrogating strokeinduced neuroinflammation and relevant secondary cell death mechanisms. Prog Neurobiol. 2017;158:94-131. 